\title{
Odour impact assessment of a large municipal solid waste landfill under different working phases
}

\author{
Naddeo V. ${ }^{1}$, Zarra T. ${ }^{1}$, Oliva G. ${ }^{1}$, Chiavola A. ${ }^{2}$, Vivarelli A. ${ }^{3}$ and Cardona G. ${ }^{3}$ \\ ${ }^{1}$ Sanitary and Environmental Engineering Division (SEED), Department of Civil Engineering, University of Salerno \\ ${ }^{2}$ Sapienza University of Rome, DICEA, via Eudossiana, 18, 00184, Rome, Italy \\ ${ }^{3}$ Ind.Eco S.r.I., SDA Monfalcone, 23, 04100, Latina, Italy \\ Received: 19/05/2018, Accepted: 27/09/2018, Available online: 04/10/2018 \\ *to whom all correspondence should be addressed: e-mail: agostina.chiavola@uniroma1.it \\ https://doi.org/10.30955/gnj.002770
}

\begin{abstract}
Odours are among the main causes of complaints in regards to environmental issues for a variety of plants, including landfills. The emissions from landfills can affect the quality of life and negatively influence the area nearby. To protect people living in the surroundings from excessive odour exposures, different environmental protection practices may be implemented. In order to optimize technical and economic aspects, various configurations should be taken into account. In this view, the odour dispersion modelling represents a suitable tool to simulate different scenarios. In the present study, the odour impact from a large landfill located in Borgo Montello (Lazio Region, Italy) has been assessed by a dispersion model. Different operating conditions were simulated, in view of minimizing the odour annoyance during the phase of temporary closure of an area of the investigated plant. The Calpuff model was selected as it is well recognized among the preferred models for assessing the long range transport of pollutants. The Odour Emission Rates, inputs to the model, were calculated based on the results of dynamic olfactometry. The outputs from the dispersion model were investigated to define the best measures for the control of the odour emissions during the most impactful operations.
\end{abstract}

Keywords: Control, dispersion model, environmental protection practices, odour annoyance.

\section{Introduction}

Landfill disposal entails the release of gases into the atmosphere. The atmospheric emissions may be also related to unpleasant odours and, thus, may cause annoyance among the resident population (Brancher and de Melo Lisboa, 2014; Chaignaud et al., 2014). In particular, the negative impacts of these types of facilities affect air quality and life conditions of people living nearby the landfills. The exposure to odour emissions is among the main causes of complaints and denunciation towards a variety of intensive and industrial plants. This problem is intrinsically linked to the management of environmental protection
These complaints represent a hindrance to the management of existing plants as well as hinder the placement of new ones (Zarra et al., 2009). The solid wastes, in particular, undergo the aerobic and anaerobic degradation of organic matter. These processes result in an intensive production of methane, carbon dioxide and volatile organic compounds. The volatile compounds, both organic and inorganic, characterized by a low odour detection thresholds, are typically the main responsible of nuisance to the near-living population (Lucernoni et al., 2016, 2017; Prata et al., 2016). Although the emission of odorous compounds are not always correlated to a health risk, it is widely reported in several studies the occurrence of symptoms as headache, nausea, stress are, (Zarra et al., 2008). It is not well defined the correlation between the odour exposure and odour annoyance due to the presence of individual and subjective factors, which imply different responses among receptors exposed to comparable odour exposure levels (Boers et al., 2016). The odour emissions from landfills are strictly dependent on the release of volatile compounds through percolate and biogas and, thus, to the technologies implemented for their management. With a view at optimizing suitable strategies to control odour exposure, specific methods for odour emissions measurement and odour impact assessment are needed (Lucernoni et al., 2016). The odour impact assessment represents an effective tool with regard to the acceptability of odour emitting activities among the population living in the surroundings. The results of the implementation of dispersion models allow the comparison between different scenarios (Schauberger et al., 2014). The overlap of the odour exposure levels resulting from different sources could be taken into account using dispersion model, retrieving information on location, source characteristics and meteorological conditions (Boers et al., 2016; Naddeo et al., 2016). Dispersion models allow the calculation of ambient concentrations; these values, with regards to odours, have to be modified to take into account the physiology of the human breathe. For this reason, the obtained 
concentrations are amplified by the peak-to-mean ratio (Piringer et al., 2015).

Odour Emission Rates (OERs) were the main input data for the dispersion model, expressed as odour unit per second (Schauberger et al., 2014). With regards to area sources, it is evaluated the Specific Odour Emission Rate (SOER), expressed as the odour units emitted from the source per surface and time unit, referring to the flow rate used for the sampling (Capelli et al., 2013). The definition of the OERs and SOERs consists of 3 main phases: odour samplings, olfactometric analysis and data elaboration (Capelli et al., 2008; Sironi et al., 2010).

Among the main techniques for the characterization of odour emissions, the sensorial methods, which use the human nose as sensor, allow the comprehension of the complexity of the odour mixture to analyze (Zhao et al., 2015; Sarkar and Hobbs, 2003). In particular, the dynamic olfactometry represents a widespread solution for the definition of odour concentrations, standardized by UNI EN 13725:2004 (Zarra et al., 2012). This technique relies on a panel of trained persons in order to reduce the subjectivity of the measurements (Capelli et al., 2008). The present manuscript show the main results with regard to a case study concerning the implementation of a dispersion model to assess the odour impact from a big landfill in the Central Italy. The CALPUFF atmospheric dispersion model was implemented in order to compare different scenarios, which different odour sources configurations and OER were related to. The investigated conditions were evaluated in terms of impacted area resulting on the territory surrounding the landfill.

The optimization of the mitigation measures for odour impact control was realized assessing the simulation of different scenarios. Different environmental protection practices were analyzed in the operating conditions and during the temporary phases which included the impactful operations of waste movement.

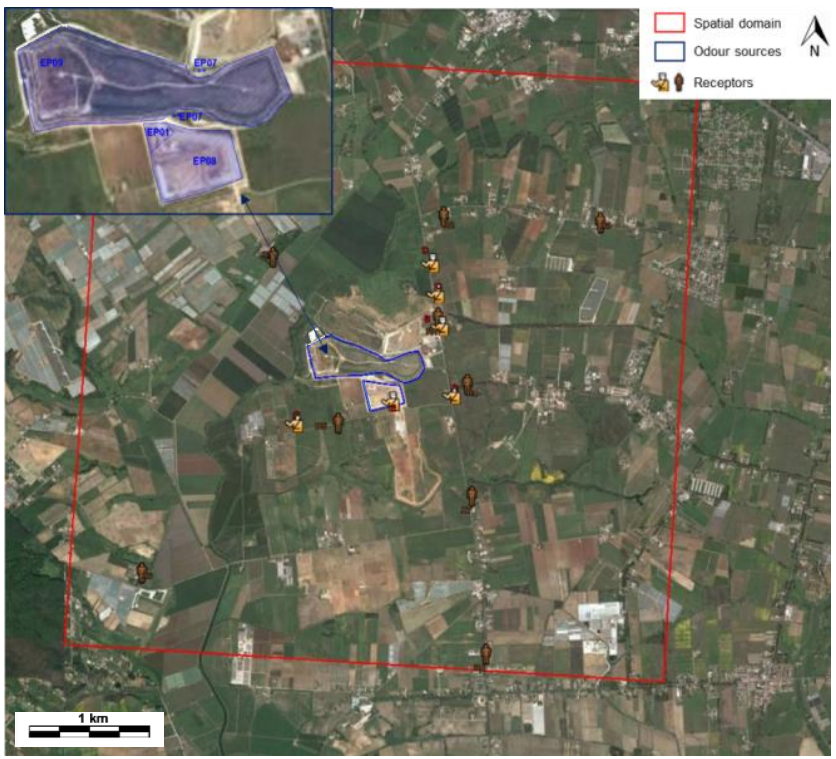

Figure 1. Identification of spatial domain, odour sources and receptors

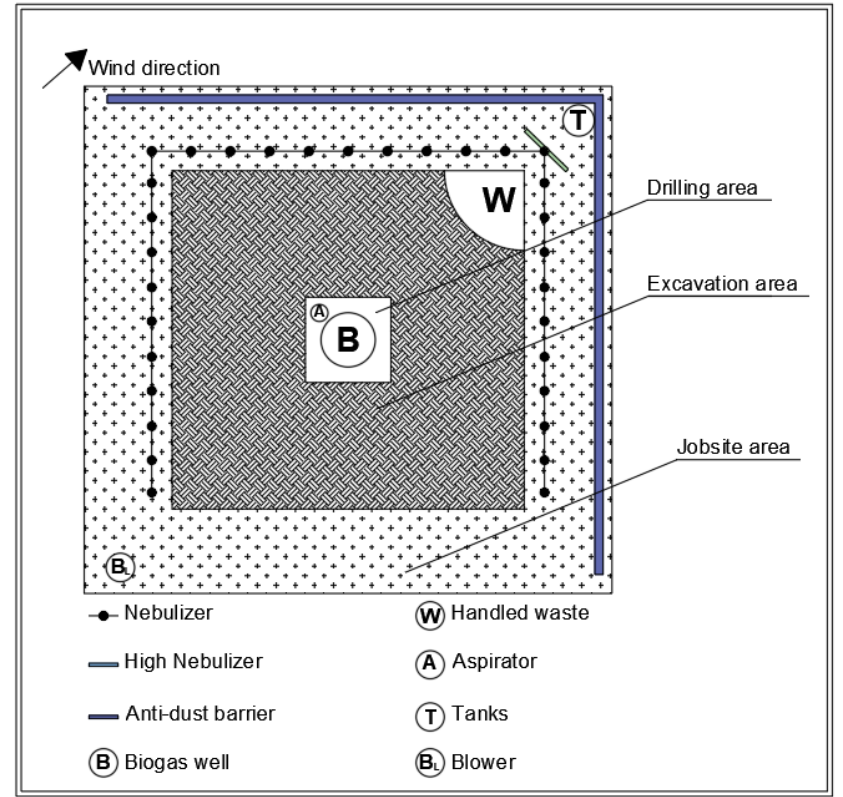

Figure 2. Mitigation measures schematization

\section{Materials and methods}

\subsection{Site description}

The studies were carried out with regard to a landfill plant located in Borgo Montello, Lazio Region (Central Italy) (Figure 1). The site is located in a rural area, $11.5 \mathrm{~km}$ far from the city center. The plant is composed of five basins, four of which result in the post-management phase with permanent cover. The main activities carried out at the active basins are: weighing, inspection and acceptance or refusal of waste; transport of waste; waste disposal; transit of vehicles. The activities carried out both at the active and post-operating basins, instead, are: management and control of the drainage and leachate collection systems; management and control of the collection and combustion systems of biogas; management of human and technological resources available at the plant.

\subsection{Odour sources characterization}

The simulated scenarios, which have been elaborated by the implementation of the dispersion model, allowed the comparison between different environmental protection measures, in the current conditions, in the working phase scenario and in the final closure prospect. In the current scenario, the active basin has an intermediate cover. The simulated project scenario provided for a temporary phase in which a layer of soil was disposed on the top of the active basin, in order to accelerate the solid waste compaction. The foreseen settlement resulted to be between 2.5 to 4 meters. Before the disposal of the load on the basin, a previous leveling of the surface was considered; in order to carry out the leveling, an intensive movement of solid waste resulted necessary. The designed manufacturing activities involved the movement of $13,750 \mathrm{~m}^{3}$ of solid waste. These working activities were simulated for 8 hours per day, five days per week, in the worst-case scenario, for a period of two months. In the working phase scenario, the active basin was simulated considering three different conditions: 
covered waste, excavation of waste, handled waste. For this reason, at this source, the odour samplings were carried out at different levels depth: $-0.5 \mathrm{~m},-1 \mathrm{~m},-4.5 \mathrm{~m}$. In Figure 2 are reported the mitigation measures which were foreseen in this phase. They consists of a nebulizers net and a high nebulizer of mask agent, an anti-dust barrier and a vacuum cleaner, all arranged along the main wind direction. In the final closure scenario, a long-term cover was designed.

The odour sources considered for all the simulated scenarios were: EPO1 (active basin, front in cultivation); EP07/1, EP07/2, EP07/3, EP07/4 (torches for biogas combustion); EP08 (active basin, front not in cultivation); EP09 (basins in post-management phase).

For each investigated source, different air samples were taken. The sampling of point sources was carried out, according to EN 13725:2003, using the 'lung' technique. Nalophan ${ }^{\circledR}$ sampling bags, with a 10 liter volume, were placed inside a rigid container (length $685 \mathrm{~mm}$, diameter $152 \mathrm{~mm}$ ). The sampling of area sources was carried out using a Flux Chamber (Scentroid SF450), with the following parameters: diameter $450 \mathrm{~mm}$, with an enclosed surface area of $0.155 \mathrm{~m}^{2}$, inlet flow of $3.9 \mathrm{lpm}$. The definition of odour concentrations was realized by Dynamic Olfactometry (DO). The analyses were conducted within 30 $\mathrm{h}$ after sampling at Laboratory of Environmental Engineering (SEED) of the University of Salerno, according to EN 13725:2003. The olfactometric analyses were carried out using a TO8 olfactometer (ECOMA, D), based on the "yes/no" method, relying on a panel composed of four trained persons.

The EP01, EP08 and EP09 sources were patterned as passive area sources, with natural wind ventilation. EP07/1, EP07/2, EP07/3, EP07/4 were patterned as channeled point sources, with forced ventilation. The localization of odour sources are reported in Figure 1.

The odour concentrations of each investigated source were used for the calculation of the OERs. The OERs for the point sources were calculated according to the equation (1).

$$
\mathrm{OER}=\mathrm{Q} \cdot \mathrm{C}_{\mathrm{OD}}
$$

In the equation (1), OER is the odour emission rate, expressed in ouE/s, $Q$ is the flow rate in $\mathrm{Nm}^{3} / \mathrm{s}$ and $\mathrm{CoD}_{\mathrm{OD}}$ is the odour concentration in $\mathrm{ou}_{\mathrm{E}} / \mathrm{m}^{3}$.

The OERs of the passive area sources were calculated multiplying the SOERs (Specific Odour Emission Rate), expressed in odorimetric units emitted per surface unit and time $\left(\mathrm{ou}_{\mathrm{E}} /\left(\mathrm{m}^{2} \mathrm{~s}\right)\right)$ and calculated according to the equation (2), for the emission source surface.

$$
\text { SOER }=\frac{Q \cdot C_{O D}}{A_{W}}
$$

In the equation (2), $Q$ is the flow rate of the neutral air stream inlet the chamber, expressed in $\mathrm{m}^{3} / \mathrm{s}$, equal to 3.9
Ipm, $\mathrm{C}_{\mathrm{OD}}$ is the odour concentration in $\mathrm{ou}_{\mathrm{E}} / \mathrm{m}^{3}, \mathrm{Aw}_{\mathrm{w}}$ is the enclosed surface area of the flux chamber, equal to $0.155 \mathrm{~m}^{2}$.

\subsection{Experimental set-up}

The odour dispersion was determined according to the guidelines suggested by US EPA, using the preferred model CALPUFF. In Figure 1 is reported the spatial domain implemented of 5,000 $\mathrm{m} \times 5,000 \mathrm{~m}$, with a square grid of receptors of 100 meter per side. The characterization of the terrain following was carried out taking into account seven vertical layers. The coefficients of the land use were selected according to Scirè et al. (2000). The full potential of CALPUFF model was possible to obtain in combination to the 3D meteorological and micro meteorological data generated by CALMET. The hourly meteorological data (wind speed and direction, pressure, temperature and rainfall), needed as input to CALMET, were acquired from MAIND, for a period of one year. The outputs of dispersion model were, for each hour and each receptor, the hourly average of the odour concentrations. These values were multiplied for the peak-to-mean (P/M) ratio, in order to obtain the peak odour concentrations. For sources at low latitude of the emission point and affected by trailing effect the $P / M$ was assumed equal to 2.3 , as suggested by the Department of Environment and Conservation (DEC, 2006). Fourteen sensitive receptors were identified as reported in Figure 1 . The odour exposure levels were calculated at an elevation of $2 \mathrm{~m}$.

\section{Results and discussion}

The outputs from the implementation of the dispersion model regarding the working phase scenario are reported in Figure 3. The numerical simulations were carried out with and without mitigation measures. The results were discussed in terms of $98^{\text {th }}$ percentile of the hourly peak odour concentration and represented on the odour impact maps. The analysis of the results highlighted that this phase resulted as a highly odour impacting phase. The movements and handling of the waste disposed at different depths was indeed envisaged during this phase. Without the implementation of the protection practises (Figure $3 \mathrm{~b}$ ), the isopleth corresponding to an odour concentration of $1 \mathrm{ou} / \mathrm{m}^{3}$, the perception threshold, covered an area of more than $9 \mathrm{~km}^{2}$. The area where the odour impact resulted "unacceptable", according to the definitions of the Regional Decree of Lombardia Region $n$. $\mathrm{IX} / 3018$, presented odour concentrations greater than $5 \mathrm{ou}_{\mathrm{E}} / \mathrm{m}^{3}$ and resulted of about $1.5 \mathrm{~km}^{2}$. By the implementation of the described mitigation measures (Figure 3a), the isopleths corresponding to the $98^{\text {th }}$ percentile of the hourly peak odour concentration, covered a smaller area. The impacted area, contained within the isopleth corresponding to $1 \mathrm{ou}_{\mathrm{E}} / \mathrm{m}^{3}$, resulted equal to $8 \mathrm{~km}^{2}$ and the maximum value of hourly peak odour concentration resulted lower than $20 \quad \mathrm{ou}_{\mathrm{E}} / \mathrm{m}^{3}$. The impacted area with a level of exposure defined as "unacceptable" resulted of about $1 \mathrm{~km}^{2}$, and the sensitive receptors exposed to a corresponding odour concentrations greater than $5 \mathrm{ou}_{\mathrm{E}} / \mathrm{m}^{3}$ decreased from five to two. The simulations of the working phase scenarios, 
both with and without the control measures, were carried out taking as reference time only two months, instead of one year.

In Figure 4 are reported the results of the operating scenario, implemented both in the current conditions and in the project scenario of final closure. In the project scenario, the hourly peak odour concentrations resulted lower than 5 ouk $/ \mathrm{m}^{3}$ over the entire investigated area. According to the IPPC-H4 English guideline, that introduces the concept of "Annoyance Potential", the odour concentration of $3 \mathrm{ou}_{\mathrm{E}} / \mathrm{m}^{3}$ was taken as reference for "moderately offensive odours".

The area affected by moderately offensive odour impact decreased from $2.2 \mathrm{~km}^{2}$ (current scenario) to $1.7 \mathrm{~km}^{2}$ in the project scenario. In this scenario, only one sensitive receptor resulted exposed to moderately offensive odour levels. a)

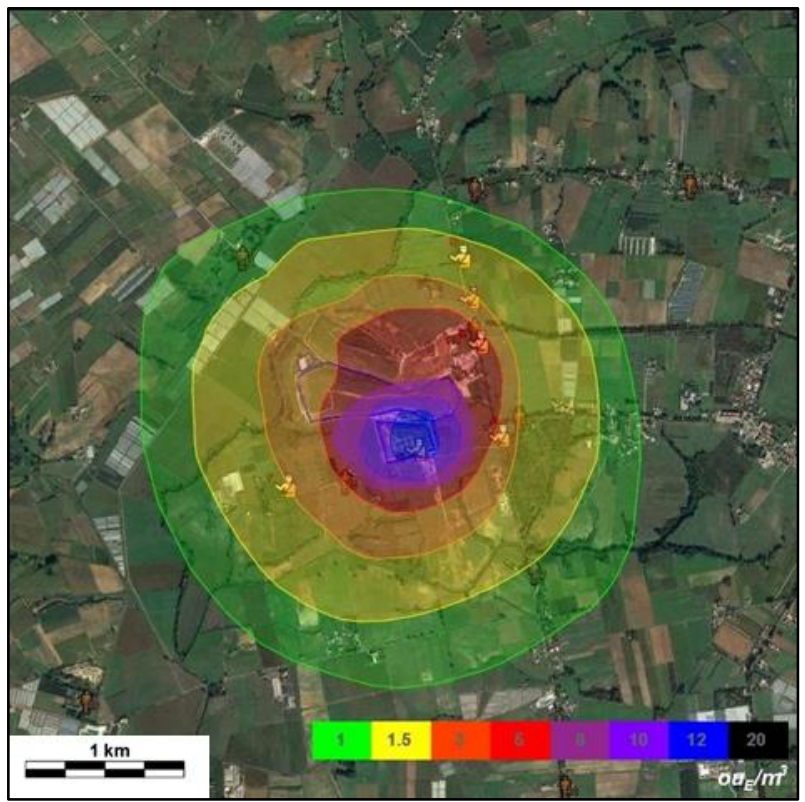

b)

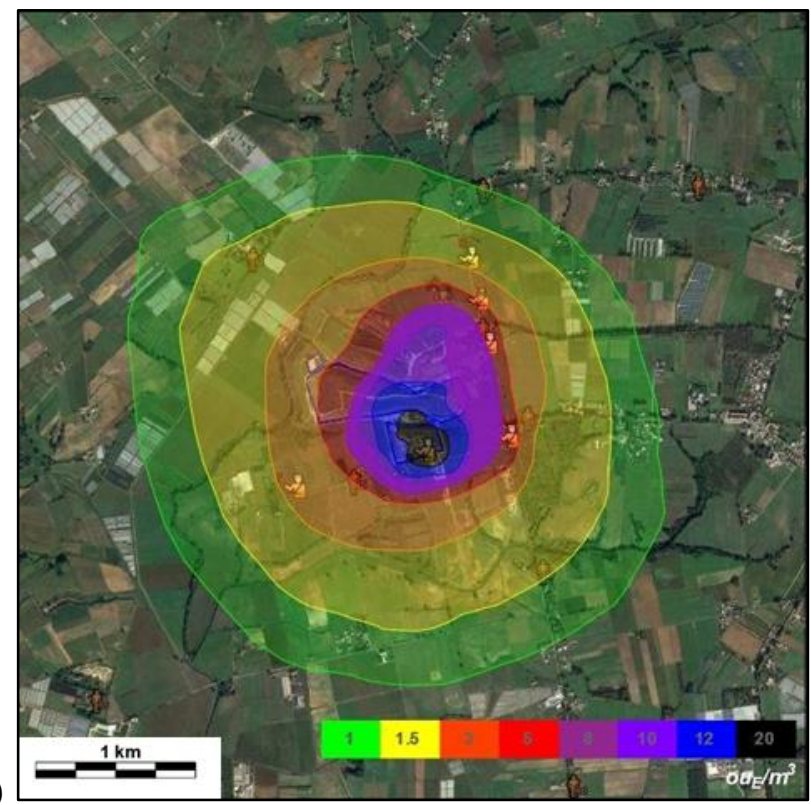

Figure 3. Comparison of the working activities scenarios with (a) and without (b) mitigation measures
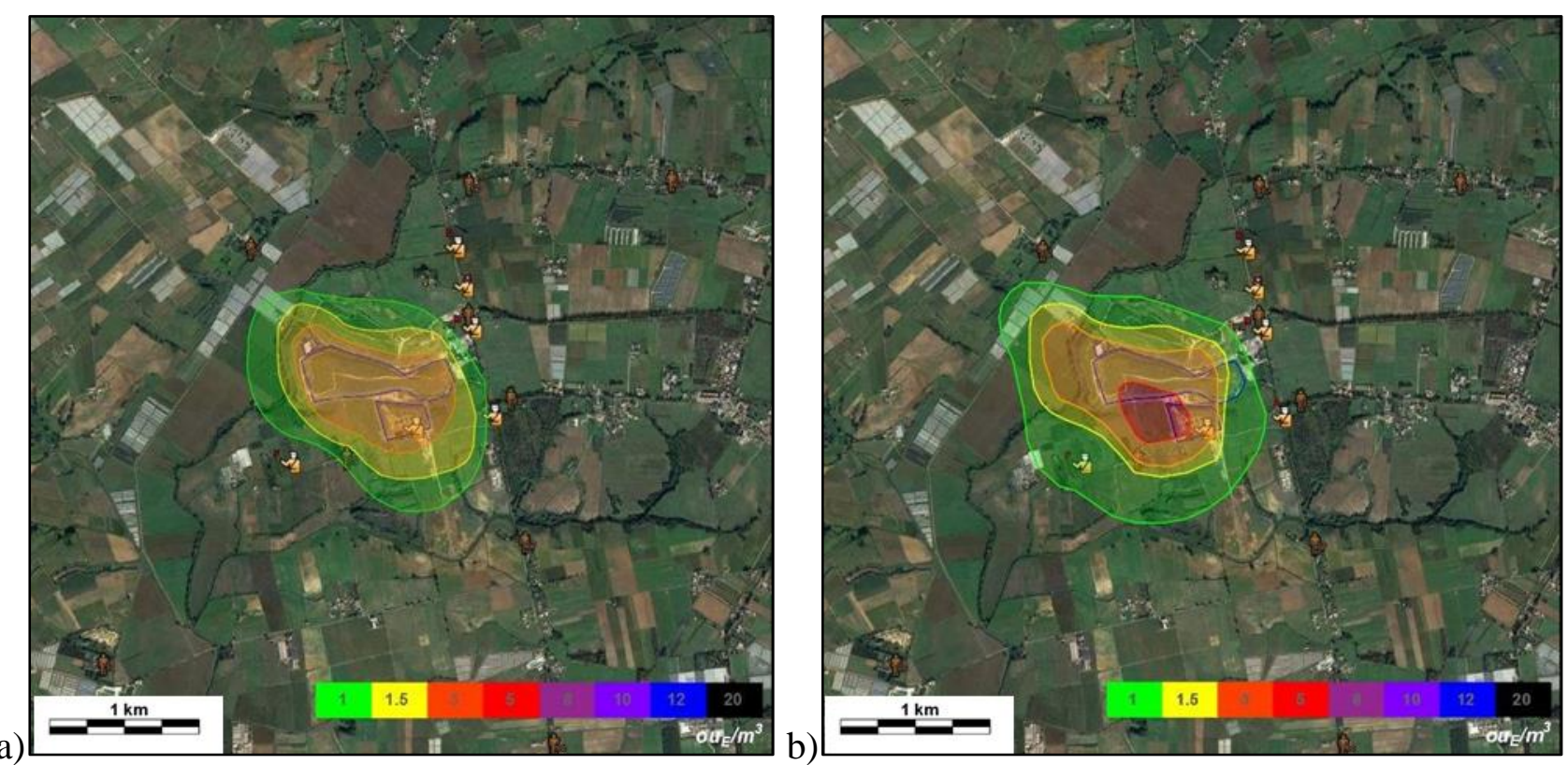

Figure 4. Comparison of the project scenario (a) and current scenario (b)

\section{Conclusions}

The dispersion model allowed to carry out a numerical simulation in order to compare different operating conditions along with a variety of mitigation measures. In that way, it resulted possible to minimize the odour exposure levels with the assessment of different operating solutions. The dispersion models implementation thus resulted in an useful tool for the optimization of mitigation strategies with the aim at evaluating odour impact surrounding a big landfill. The results from the implementation may be evaluated during the decision- 
making process. The exposure levels resulted to be significant during the working phase; however, this phase has an expected duration of two months and the designed measures allowed a considerable decreasing of the levels of exposure at the receptors closer to the investigated landfill. In addition, should be noted that the modelling of this phase was carried out referring to its real expected duration, without spreading the considerable odour emissions over one year, the reference time considered for the other simulated scenarios. In the project scenario, the hourly peak odour concentrations resulted lower than 5 ou $/ \mathrm{m}^{3}$ and, therefore, below the threshold considered "unacceptable" according to the above-mentioned Regional Decree. The isopleths of the odour concentrations resulted mainly influenced by the weather conditions and not by the territory morphology which is flat.

\section{References}

Boers D., Geelen L., Erbrink H., Smit L.A.M., Heederik D., Hooiveld M., Yzermans C.J., Huijbregts M. and Wouters I.M. (2016), The relation between modeled odor exposure from livestock farming and odor annoyance among neighboring residents. International Archives of Occupational and Environmental Health, 89, 521-530. doi:10.1007/s00420-015-1092-4.

Capelli L., Sironi S. and Del Rosso R. (2013), Odor sampling: techniques and strategies for the estimation of odor emission rates from different source types. Sensors, 13, 938-955. doi:10.3390/s130100938.

Capelli L., Sironi S., Del Rosso R., Céntola P. and II Grande M. (2008), A comparative and critical evaluation of odour assessment methods on a landfill site. Atmospheric Environment, 42, 7050-7058, doi:10.1016/j.atmosenv.2008. 06.009 .

Brancher M. and Lisboa H.D.M. (2014), Odour impact assessment by community survey. Chemical Engineering Transactions, 40(I), 139-144, http://doi.org/10.3303/CET144 0024.

Chaignaud M., Cariou S., Poette J., Fages M., Despres F. and Fanlo J. (2014), A new method to evaluate odour annoyance potential. Chemical Engineering Transactions, 40, 13-18.

Chemel C., Riesenmey C., Batton-hubert M. and Vaillant H. (2012), Odour-impact assessment around a land fill site from weather-type classification, complaint inventory and numerical simulation. Journal of Environmental Management, 93(1), 85-94.

Department of Environment and Conservation (DEC). (2006), Technical notes - Assessment and management of odour from stationary sources in NSW

Lucernoni F., Capelli L., Busini V. and Sironi S. (2017), A model to relate wind tunnel measurements to open field odorant emissions from liquid area sources. Atmospheric Environment, 157, 10-17. doi:10.1016/j.atmosenv.2017.03. 004.

Lucernoni F., Capelli L. and Sironi S. (2016), Comparison of different approaches for the estimation of odour emissions from landfill surfaces. Waste Management, doi:10.1016/ j. wasman.2016.09.041.

Naddeo V., Zarra T., Oliva G., Chiavola A. and Vivarelli A. (2016), Environmental odour impact assessment of landfill expansion scenarios: case study of Borgo Montello (Italy). Chemical Engineering, 54.
Piringer M., Knauder W., Petz E. and Schauberger G. (2015), A comparison of separation distances against odour annoyance calculated with two models. Atmospheric Environment, 116, 22-35. doi:10.1016/j.atmosenv.2015.06. 006.

Prata A.A., Santos J.M., Beghi S.P., Fernandes I.F., Vom Marttens L.L.C., Pereira Neto L.I., Martins R.S., Reis N.C. and Stuetz R.M. (2016), Dynamic flux chamber measurements of hydrogen sulfide emission rate from a quiescent surface - A computational evaluation. Chemosphere, 146, 426-434. doi:10.1016/j.chemosphere.2015.11.123.

Sarkar U. and Hobbs S.E. (2003), Landfill odour: assessment of emissions by the flux footprint method, 18, 155-163. http://doi.org/10.1016/S1364-8152(02)00071-3.

Schauberger G., Piringer M. and Heber A.J. (2014), Odour emission scenarios for fattening pigs as input for dispersion models: A step from an annual mean value to time series. Agriculture, Ecosystems and Environment, 193, 108-116. http://doi.org/10.1016/j.agee.2014.04.030.

Schiffman S.S., Walker J.M., Dalton P., Lorig S., Raymer J.H., Shusterman D. and Dalton P. (2008), Potential health effects of odor from animal operations, wastewater treatment, and recycling of byproducts potential health effects of odor from animal operations, Wastewater Treatment, and Recycling of Byproducts, 0813 (March 2016). http://doi.org/10.1300/ J096v07n01.

Scire J.S., Robe F.R., Fernau M.E. and Yamartino R.J. (2000), A User's Guide for the CALMET Meteorological Model, Version 5. Earth Tech Inc., Concord, MA.

Sironi S., Capelli L., Céntola P., Del Rosso R. and Pierucci S. (2010), Odour impact assessment by means of dynamic olfactometry, dispersion modelling and social participation. Atmospheric Environment, 44, 354-360. doi:10.1016/j.atmosenv.2009.10.029.

Zarra T., Naddeo V. and Belgiorno V. (2009a). A novel tool for estimating the odour emissions of composting plants in air pollution management. Global NEST Journal, 11(4), 477-48.

Zarra T., Naddeo V., Giuliani S. and Belgiorno V. (2010), Optimization of field inspection method for odour impact assessment. Chemical Engineering Transactions, 23, 93-98.

Zarra T., Reiser M., Naddeo V. and Belgiorno V. (2012), A comparative and critical evaluation of different sampling materials in the measurement of odour concentration by dynamic olfactometry. Chemical Engineering Transactions, 30, 307-312.

Zhao Y., Lu W. and Wang H. (2015), Volatile trace compounds released from municipal solid waste at the transfer stage: Evaluation of environmental impacts and odour pollution. Journal of Hazardous Materials, 300, 695-701. 